\title{
Vitamin D status among patients visiting a tertiary care center in Riyadh, Saudi Arabia: a retrospective review of 3475 cases
}

\author{
Hanan Alfawaz ${ }^{1,2^{*}}$, Hani Tamim ${ }^{3}$, Shmeylan Alharbi ${ }^{4}$, Saleh Aljaser ${ }^{5,6}$ and Waleed Tamimi ${ }^{7}$
}

\begin{abstract}
Background: Vitamin D deficiency has been implicated in several chronic, non-communicable diseases independent of its conventional role in bone and calcium homeostasis. In this retrospective study, we determined the prevalence of vitamin D deficiency and its association to several cardiometabolic indices among patients visiting King Abdulaziz Medical City (KAMC), a tertiary hospital in Riyadh, Saudi Arabia.

Methods: A total of 3475 charts of out-patient subjects who visited KAMC from September 2009 until December 2010 were reviewed and included. Variables of interest included measurements of vitamin D status, glycemic and renal profile, as well as trace elements (calcium and phosphorous).

Results: The over-all prevalence of vitamin D deficiency in the cohort studied was $78.1 \%$ in females and $72.4 \%$ in males. $25(\mathrm{OH}$ ) vitamin D was significantly associated with increasing age and weight ( $p$-values $<0.0001$ and 0.005 , respectively). It was also positively associated with albumin, calcium and phosphorous ( $p$-values $<0.0001,<0.0001$ and 0.0007 , respectively) and negatively associated with alkaline phosphatase as well as circulating levels of PTH ( $p$-values 0.0002 and 0.0007 , respectively).

Conclusion: In conclusion, vitamin D deficiency is overwhelmingly common among patients seen at KAMC regardless of the medical condition, and it is significantly associated with increasing age, weight and markers of calcium homeostasis. Findings of the present study further stress the spotlight on vitamin D deficiency epidemic in the country and region in general.
\end{abstract}

Keywords: Vitamin D, Vitamin D deficiency, Saudi

\section{Background}

Recent epidemiologic studies have found out an unpredictably high prevalence of vitamin D deficiency in apparently healthy adults living in different countries, which could be a major health problem in the future $[1,2]$. Adequate vitamin D status has important clinical advantages in decreasing risk of many diseases such as cancer [3-6], diabetes mellitus, cardiovascular [7] and autoimmune diseases [8]. Evidences from clinical and epidemiological studies support a possible relationship between low vitamin $\mathrm{D}$ status and chronic disease

\footnotetext{
* Correspondence: halfawaz@ksu.edu.sa

'Department of Food Science and Nutrition, College of Food Science and Agriculture King Saud University, P. O. Box 22452, Riyadh 11495, Saudi Arabia ${ }^{2}$ Department, College of Science, Prince Mutaib Chair for Biomarkers of Osteoporosis, Biochemistry, King Saud University, Riyadh, Saudi Arabia Full list of author information is available at the end of the article
}

progression such as obesity, hypertension and diabetes mellitus [9-11]. Studies in Saudi Arabia, the United Arab Emirates, Australia, Turkey, India, and Lebanon, reported that 30 to $50 \%$ of children and adults had 25 hydroxyvitamin D levels under $20 \mathrm{ng} / \mathrm{ml}$ [12-15]. Saudi Arabia belongs to one of the sunniest regions in the world, and while the Saudi population should have adequate sun exposure, vitamin $\mathrm{D}$ deficiency remains prevalent in the country [16]. Various reasons include protection from strong heat during daytime, genetic and diet. Vitamin D deficiency was found to be very common among Saudi males and females [16-20]. Ardawi et al. found that vitamin D deficiency was common among older and obese Saudi men [21]. Findings from Al-Daghri et al. indicated severe hypovitaminosis D as more common among non-diabetic than diabetic Saudis [22]. 
Several studies have also reported conflicting findings on the relationship between vitamin D status and obesity. Results of Al-Elq et al. study found an inverse relationship between vitamin D and BMI in Saudi males but not in females which appears that obesity is protective against vitamin D deficiency [23]. While negative association was found in many studies [24-28], some observed no relationship [29,30]. The mechanism behind such an association is that elevated concentrations of 1-25-vit D stimulate lipogenesis and inhibit lipolysis in cultured human adipocytes, leading to accumulation of fat [31]. Additionally, 1, 25-vitamin D inhibits the expression of adipocyte uncoupling protein 2 (UCP2), which would cause a reduction in the adipocyte's metabolic efficiency [32]. Cumming et al. found that vitamin D and calcium were more effective in reducing systolic blood pressure than calcium alone [33]. Furthermore, many studies reported a positive association between $1,25(\mathrm{OH}) 2 \mathrm{D}$ and vitamin D inadequacy and hypertension [34-36]. Some studies nevertheless reported conflicting results on the link between vitamin D intake and blood pressure $[37,38]$. Low serum vitamin D levels elevate the risk for early-stage diabetes (Pre-DM), hypertension (Pre-HTN) [37] and DM [39-41]. On the other hand, many studies reported no association between vitamin $\mathrm{D}$ deficiency and type 2 diabetes mellitus $[42,43]$. In the present study, we examined the relationship between serum levels of 25hydroxyvitamin D $(25[\mathrm{OH}] \mathrm{D})$, Parathyroid Hormone (PTH), obesity and selected cardiovascular disease risk factors in Saudi subjects.

\section{Methods}

In this single-center retrospective study done in the outpatient department of King Abdulaziz Medical City, Riyadh, Saudi Arabia, a total of 3475 subjects' charts were reviewed from September 2009 until December 2010. There were 2719 (78\%) females and 756 (22\%) males. Vitamin D $(25[\mathrm{OH}] \mathrm{D})$ was measured using High Performance Liquid Chromatography (HPLC). Data was collected from the laboratory master database of the Clinical Biochemistry section, Department of Pathology and Laboratory Medicine, in KAMC. In addition to vitamin D2, other laboratory tests such as fasting blood sugar (FBG), $\mathrm{HbA} 1 \mathrm{C}$, and PTH were also noted.

The corresponding medical record number of those patients were utilized to obtain the following information from Quadramed and/or medical files: Height, weight, blood pressure, HbA1c, albumin, creatinine, BUN, alkaline phosphatase, calcium, phosphorous and parathormone. All clinical parameters were measured at the same time or close to the date of vitamin D measurement. The study has been approved by the [Institutional Review Board (IRB)] Clinical Research Ethics Committee in KAMC.

\section{Data analysis}

Data was analyzed using the Statistical Package for the Social Sciences (SPSS version 16.0, Chicago, IL, USA). Frequencies were expressed in percentages (\%) and continuous variables were presented as mean \pm standard deviation. Variables that were not normally distributed (alkaline phosphatase, BUN, creatinine, 25(OH) vitamin D, and PTH) were transformed and normalized prior to parametric analysis (Pearson bivariate correlation). Student independent T-test was done to compare means of normally distributed variables and Mann-Whitney U-test for variables that are non-Gaussian. Chi-Square test was used to compare frequencies. Significance was set at $p<0.05$.

\section{Results}

Figure 1 shows the differences in the prevalence vitamin $\mathrm{D}$ deficiency according to severity across genders using different cut-off values. Females had a significantly higher prevalence of $25(\mathrm{OH}) \mathrm{D}<25 \mathrm{nmol} / \mathrm{L}$ than males (48.8\% versus $36.1 \%$; $p$-value 0.0001 ) as well as a higher prevalence of $25(\mathrm{OH})$ vitamin $\mathrm{D}<50 \mathrm{nmol} / \mathrm{L}$ (78.1\% versus $72.4 \%$; $p$-value 0.0012$)$. Using the same cut-off, it can be observed that the over-all prevalence of vitamin $\mathrm{D}$ deficiency in the cohort studied was $78.1 \%$ in females and $72.4 \%$ in males (Figure 1).

Table 1 describes the general characteristics of subjects and the associations of $25(\mathrm{OH})$ vitamin $\mathrm{D}$ to the different parameters measured. $25(\mathrm{OH})$ vitamin $\mathrm{D}$ was significantly associated with increasing age and weight ( $p$-values < 0.0001 and 0.005 , respectively). Furthermore, 25(OH) vitamin D was modestly, but significantly associated with increasing systolic blood pressure $(p=0.03)$. Among the biochemical parameters, $25(\mathrm{OH})$ vitamin $\mathrm{D}$ was positively associated with albumin, calcium and phosphorous ( $p$-values $<0.0001,<0.0001$ and 0.0007 , respectively) and negatively associated with alkaline phosphatase as well as circulating levels of PTH ( $p$-values 0.0002 and 0.0007, respectively). It is worthy to note that the prevalence of obesity in the cohort studied is $21.9 \%$, while the prevalence of morbid obesity was $44.2 \%$ (not shown in table).

Table 2 shows the comparison of the different variables using different cut-offs for $25(\mathrm{OH})$ vitamin $\mathrm{D}$. Across all groups, subjects categorized to be in the upper half ( $\geq 25, \geq 50$ and $\geq 75 \mathrm{nmol} / \mathrm{L}$ ) were significantly older ( $p$-values $<0.0001,<0.0001$ and 0.0003 , respectively) and had significantly higher levels of serum albumin ( $p$-values $0.0002,<0.0001$ and 0.0021 , respectively) and calcium ( $p$-values $<0.0001,<0.0001$ and 0.0029 , respectively) than those in the lower half. In the first grouping $(<25$ and $\geq 25 \mathrm{nmol} / \mathrm{L})$, subjects whose $25(\mathrm{OH})$ vitamin $\mathrm{D}$ levels were $\geq 25 \mathrm{nmol} / \mathrm{L}$ had significantly higher systolic and diastolic blood pressure as well as BMI ( $p$-values < $0.0001,0.0017$ and $<0.0001$, respectively) than subjects with $25(\mathrm{OH})$ vitamin $\mathrm{D}<25 \mathrm{nmol} / \mathrm{L})$. Among the 


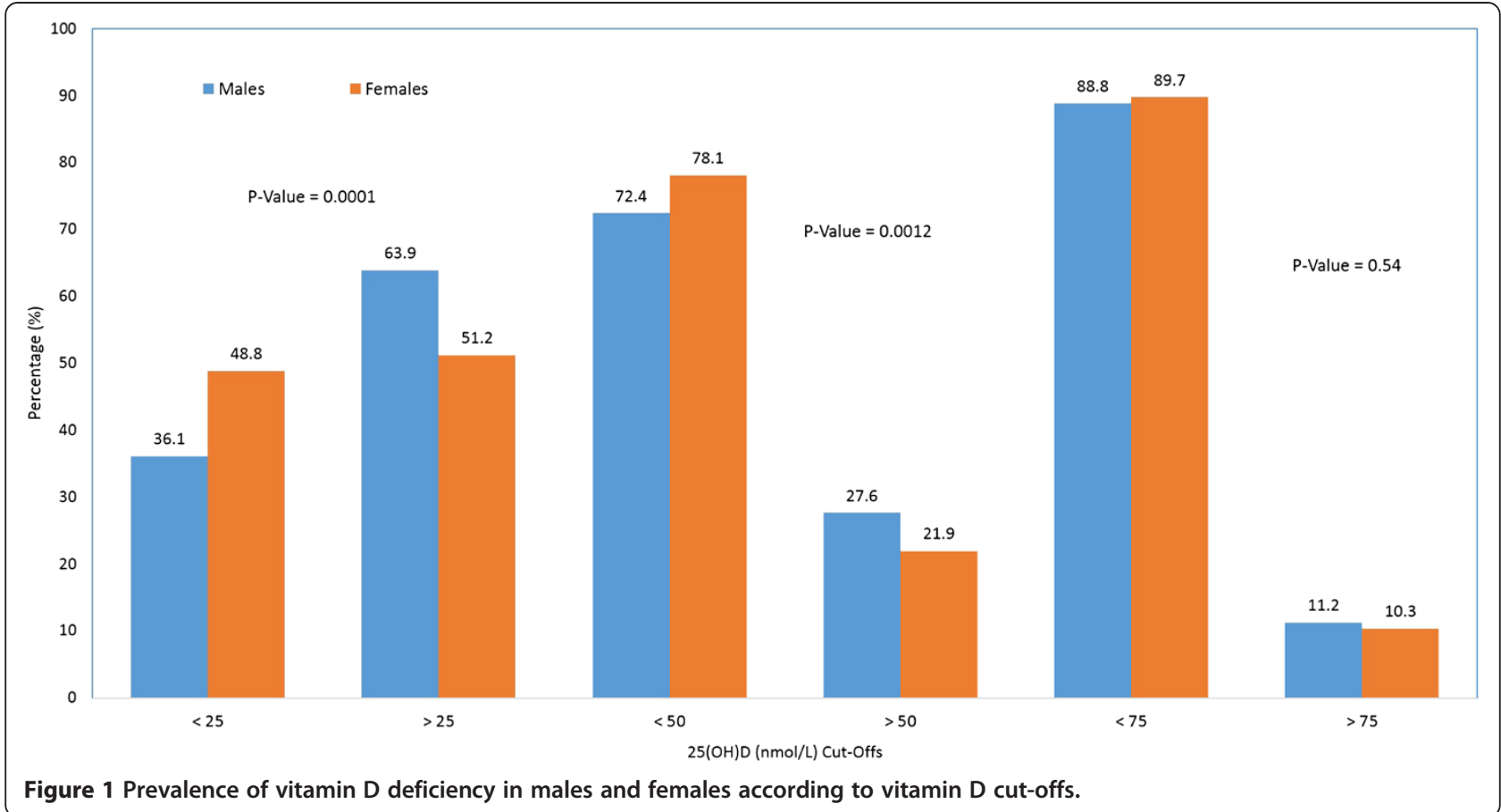

biochemical parameters measured, those in the upper half ( $\geq 25 \mathrm{nmol} / \mathrm{L}$ ) had a significantly higher blood fasting glucose, BUN and phosphorous (p-values $<0.0001,0.0002$ and $<0.0001$, respectively) as well as a significantly lower alkaline phosphatase $(p$-value $=0.0001)$ than the lower half $(<25 \mathrm{nmol} / \mathrm{L})$. In the second grouping, serum alkaline

\section{Table 1 General characteristic of subjects}

\begin{tabular}{lccc}
\hline Parameters & Mean \pm SD & $\mathbf{R}^{2}$ & P-value \\
\hline N =3475 (Males = 756; Females = 2719) & & \\
Age (years) & $46.9 \pm 16.3$ & 0.15 & $<0.0001$ \\
Weight (kg) & $75.2 \pm 18.2$ & -0.06 & 0.005 \\
Height (cm) & $147.0 \pm 18.0$ & 0.01 & 0.64 \\
BMl (kg/ m ${ }^{2}$ ) & $36.4 \pm 13.8$ & -0.03 & 0.17 \\
Systolic blood pressure (mmHg) & $122.0 \pm 19.0$ & 0.05 & 0.03 \\
Diastolic blood pressure (mmHg) & $71.0 \pm 11.0$ & 0.04 & 0.09 \\
Glucose (mmol/L) & $6.4 \pm 3.0$ & 0.02 & 0.24 \\
HbA1c (\%) & $7.0 \pm 1.9$ & 0.01 & 0.70 \\
Albumin (g/L) & $46.0 \pm 4.9$ & 0.11 & $<0.0001$ \\
Alkaline phosphatase (U/L)\# & $97.1 \pm 82.7$ & -0.09 & 0.0002 \\
BUN (mmol/L) & $5.1 \pm 3.4$ & 0.03 & 0.12 \\
Calcium (mmol/L) & $2.34 \pm 0.15$ & 0.14 & $<0.0001$ \\
Creatinine (umol/L)\# & $79.4 \pm 70.2$ & -0.01 & 0.48 \\
25OH Vitamin D (nmol/L)\# & $35.5 \pm 30.6$ & 1.00 & - \\
Phosphorus (mmol/L) & $1.14 \pm 0.23$ & 0.09 & 0.0007 \\
PTH (mmol/L)\# & $34.2 \pm 58.3$ & -0.10 & 0.0007 \\
\hline No & &
\end{tabular}

Note: Data presented as mean \pm standard deviation; $R^{2}$ is the correlation coefficients compared to the concentration of $25 \mathrm{OH}$ Vitamin D; \#denotes non-Gaussian variable. phosphatase was also observed to be significantly lower in the upper half $(\geq 50 \mathrm{nmol} / \mathrm{L})$ as compared to the lower half $(<50 \mathrm{nmol} / \mathrm{L})(p$-value $=0.0082)$. Both the upper half of the 2nd and 3rd group ( $\geq 50$ and $\geq 75 \mathrm{nmol} / \mathrm{L}$ ) had significantly lower PTH levels ( $p$-values $=0.034$ and 0.039 , respectively) than their corresponding lower halves $(<50$ and $<75 \mathrm{nmol} / \mathrm{L})$. The rest of the comparisons done for other variables not mentioned in all groups were non-significant. Worthy of mention however is the mean HBA1c among subjects whose $25(\mathrm{OH})$ vitamin $\mathrm{D}$ is $>75 \mathrm{nmol}$ which, while not significant, is considered the lowest as compared to the rest of the groups.

\section{Discussion}

The major finding in the present one-year retrospective study is the overwhelming prevalence of vitamin D deficiency among Saudi patients seen at the outpatient clinics of KAMC. This confirms, and adds to the increasingly accumulating evidence that vitamin D deficiency in Saudi Arabia, specifically in urban areas such as the capital Riyadh, is alarmingly high [12-22]. Furthermore, the results of local epidemiologic findings on vitamin $\mathrm{D}$ deficiency, including the present study, are undeniably consistent, regardless of the methods used to quantify $25(\mathrm{OH}) \mathrm{D}$, strengthening the premise that vitamin $\mathrm{D}$ deficiency is an epidemic in Saudi Arabia. What makes the present study unique is the arguably larger sample size as compared to previous studies, and that the type of cohort used can be considered representative of the general population, since patients referred to KAMC are not limited to the capital Riyadh, and that inclusion 
Table 2 Comparison of variables using different vitamin d cut-off values (t-test)

\begin{tabular}{|c|c|c|c|c|c|c|}
\hline \multirow[t]{2}{*}{ Parameters } & \multicolumn{6}{|c|}{$25(\mathrm{OH})$ vitamin $D$ cut-offs (nmol/L) } \\
\hline & $<25$ & $\geq 25$ & $<50$ & $\geq 50$ & $<75$ & $\geq 75$ \\
\hline $\mathrm{N}$ & 1601 & 1874 & 2672 & 803 & 3110 & 365 \\
\hline Age (years) & $43.5 \pm 16.3$ & $49.9 \pm 15.8^{* *}$ & $45.7 \pm 16.3$ & $51.0 \pm 15.8^{* *}$ & $46.6 \pm 16.3$ & $49.8 \pm 15.8^{* *}$ \\
\hline BMI $\left(\mathrm{kg} / \mathrm{m}^{2}\right)$ & $35.1 \pm 12.6$ & $37.9 \pm 14.8^{* *}$ & $37.1 \pm 14.9$ & $33.8 \pm 11.5^{* *}$ & $37.0 \pm 14.0$ & $30.3 \pm 7.7^{* *}$ \\
\hline Systolic blood pressure (mmHg) & $120.0 \pm 19.0$ & $124.0 \pm 19.0^{* *}$ & $122.0 \pm 19.0$ & $123.0 \pm 17.0$ & $122.0 \pm 19.0$ & $121.0 \pm 16.0$ \\
\hline Diastolic blood pressure (mmHg) & $70.0 \pm 11.0$ & $72.0 \pm 11.0^{* *}$ & $71.0 \pm 11.0$ & $71.0 \pm 11.0$ & $71.0 \pm 11.0$ & $70.0 \pm 10.0$ \\
\hline Glucose (mmol/L) & $6.2 \pm 2.6$ & $6.5 \pm 3.4^{* *}$ & $6.4 \pm 2.9$ & $6.4 \pm 3.4$ & $6.4 \pm 3.0$ & $6.6 \pm 2.8$ \\
\hline $\mathrm{HbA1c}(\%)$ & $6.9 \pm 1.8$ & $7.1 \pm 1.9$ & $7.1 \pm 1.9$ & $6.9 \pm 1.8$ & $7.0 \pm 1.9$ & $6.8 \pm 1.9$ \\
\hline Albumin $(\mathrm{g} / \mathrm{L})$ & $45.6 \pm 5.1$ & $46.3 \pm 4.5^{* *}$ & $45.7 \pm 5.0$ & $46.9 \pm 3.9^{* *}$ & $45.9 \pm 4.9$ & $46.9 \pm 4.0^{* *}$ \\
\hline Alkaline phosphatase (U/L) & $106.0 \pm 103.0$ & $90.0 \pm 60.0^{* *}$ & $100.0 \pm 88.0$ & $88.0 \pm 69.0^{* *}$ & $98.0 \pm 85.0$ & $91.0 \pm 58.0$ \\
\hline BUN (mmol/L) & $4.9 \pm 3.5$ & $5.3 \pm 3.3^{* *}$ & $5.0 \pm 3.5$ & $5.2 \pm 2.8$ & $5.1 \pm 3.5$ & $5.0 \pm 2.2$ \\
\hline Calcium (mmol/L) & $2.3 \pm 0.2$ & $2.4 \pm 0.2^{* *}$ & $2.3 \pm 0.2$ & $2.4 \pm 0.1^{* *}$ & $2.33 \pm 0.15$ & $2.37 \pm 0.15^{* *}$ \\
\hline Creatinine (umol/L) & $77.0 \pm 65.0$ & $82.0 \pm 74.0$ & $80.0 \pm 75.0$ & $77.0 \pm 53.0$ & $80.0 \pm 74.0$ & $73.0 \pm 21.0$ \\
\hline Phosphorus (mmol/L) & $1.11 \pm 0.24$ & $1.16 \pm 0.22^{* *}$ & $1.13 \pm 0.24$ & $1.15 \pm 0.21$ & $1.13 \pm 0.23$ & $1.15 \pm 0.22$ \\
\hline PTH (pmol/L) & $38.0 \pm 67.0$ & $31.0 \pm 51.0$ & $36.0 \pm 62.0$ & $28.0 \pm 48.0^{* *}$ & $36.0 \pm 61.0$ & $25.0 \pm 35.0^{*}$ \\
\hline
\end{tabular}

Note: Data presented as mean \pm standard deviation; ${ }^{*}$ denotes significance at $<0.05$ level; ${ }^{* *}$ denotes significance at $<0.01$ level.

of cases was not stringent, making the selection of cases devoid of bias.

Among the associations of $25(\mathrm{OH})$ vitamin $\mathrm{D}$ and cardiometabolic variables elicited, it is worthy to emphasize that vitamin D deficiency is less common among the elderly in the Saudi population. Looking back at the mean glucose and HBA1c levels of the cohort, it is apparent that majority of the subjects included had diabetes mellitus type 2 (DMT2), and age-related disease. Subjects who harbor this disease have been observed to have higher levels of $25(\mathrm{OH}) \mathrm{D}$ than their non-diabetic counterparts [22-45]. Part of the explanation lies in the almost mandatory multivitamin supplementation (multivitamins contain $400 \mathrm{IU}$ vitamin $\mathrm{D}$ on average) given to Saudi elderly patients and those with DMT2 as well as other anti-DM medications that have been observed to augment circulating levels of $25(\mathrm{OH})$ vitamin D $[45,46]$. Another obvious risk factor from the present cohort is obesity. The mean BMI for the entire cohort fell within this category $(36.4 \pm 13.8)$. Obesity is a well-known cardiovascular risk factor associated with vitamin $\mathrm{D}$ deficiency, more so for the Arab population where vitamin $\mathrm{D}$ correction has modest, if not negligible effect on BMI [47-49].

With regards to other biochemical parameters measured, the association of $25(\mathrm{OH})$ vitamin $\mathrm{D}$ to albumin is expected in the study. It has been established that majority of circulating vitamin $\mathrm{D}$ is bound both to vitamin $\mathrm{D}$ binding protein and albumin [50,51]. The same expected significant association is true for vitamin $\mathrm{D}$ and calcium, in which the former is directly involved in calcium homeostasis. Lastly, the lack of significant difference in PTH levels of those below and above $25 \mathrm{nmol} / \mathrm{L}$ is consistent with the findings of Al-Saleh et al., where $\mathrm{PTH}$ levels remain normal despite having low to very low 25(OH) vitamin D levels, a unique feature among the Arabian cohort [52]. Nevertheless, the present study showed a significant and inverse association between PTH and vitamin D status, but differences in levels were only prominent if $<50$ or $<75 \mathrm{nmol} / \mathrm{L}$ was used. Longitudinal studies are needed to confirm at what level of vitamin D status correction in the Arab cohort is needed to elicit a PTH response.

The study acknowledges several limitations. The retrospective and cross-sectional nature of the study as well as the population selected from the general outpatient clinics limit the findings to the information available at the database. The study was not able to consider confounding variables and other risk factors that can be used to adjust analysis such as presence of DMT2, skin color, sun exposure information and season where vitamin D was measured, the latter 2 factors being considered as very important predictors for vitamin D status in this geographical region [53]. Nevertheless, the study has several strengths and that includes the large sample size and the inclusion of all adult subjects whose vitamin D status was measured at a given time frame in one institution, which removed selection bias and increased the generalizability of present findings.

\section{Conclusion}

In conclusion, vitamin $\mathrm{D}$ deficiency is overwhelmingly common among patients seen at KAMC regardless of the medical condition, further stressing the spotlight on this epidemic in the country and region in general. Aggressive 
measures should not be limited on the diagnosis, and multi-institutional involvement that includes policy makers, government and private companies should carry out public health campaigns to increase awareness and limit the spread of vitamin D deficiency engulfing the nation.

\section{Competing interests}

The authors declare that they have no competing interests.

\section{Authors' contributions}

HF designed study, collected and revised data, drafted the initial and the final version of the manuscript. HT carried out data analysis and interpretation. SJ, SH and WT revised data and manuscript. All authors provided intellectual contributions to the manuscript and has read and approved the final version.

\section{Acknowledgements}

The authors are grateful to Mr. Nawaf Al Otaibi, Mr. Adel Al Sadhan and Mr. Bandar Al Ganam for their assistance in data collection and data entry. The authors would like to thank King Abdullah International Medical Research Center, National Guard Health Affairs, Saudi Arabia, for supporting this project.

\section{Author details}

'Department of Food Science and Nutrition, College of Food Science and Agriculture King Saud University, P. O. Box 22452, Riyadh 11495, Saudi Arabia. ${ }^{2}$ Department, College of Science, Prince Mutaib Chair for Biomarkers of Osteoporosis, Biochemistry, King Saud University, Riyadh, Saudi Arabia. ${ }^{3}$ Department of Internal Medicine, Clinical Research Institute, American University of Beirut Medical Center, Beirut, Lebanon. ${ }^{4}$ Pharmaceutical Care Department, College of Pharmacy, King Saud bin Abdulaziz University for Health Sciences, Riyadh, Saudi Arabia. ${ }^{5}$ Diabetes Care Program, King Abdulaziz Medical City, Riyadh National Guard, Riyadh, Saudi Arabia. ${ }^{6}$ College of Medicine, King Saud Bin Abdulaziz University for Health Sciences, Riyadh, Saudi Arabia. ${ }^{7}$ Department of Pathology \& Lab Medicine, College of Medicine, King Saud Bin Abdulaziz University for Health Sciences, Riyadh, Saudi Arabia.

Received: 20 November 2013 Accepted: 5 February 2014 Published: 13 February 2014

\section{References}

1. Rucker D, Allan JA, Fick GH, Hanley DA: Vitamin D insufficiency in a population of healthy western Canadians. CMAJ 2002, 166:1517-1524.

2. Hasehmipour S, Larijani B, Adibi H, Javadi E, Sedaghat M, Pajouhi M, Soltani A, Shafaei AR, Hamidi Z, Fard AR, Hossein-Nezhad A, Booya F: Vitamin D deficiency and causative factors in the population of Tehran. BMC Public Health 2004, 4:38.

3. Garland CF, Gorham ED, Mohr SB, Grant WB, Giovanucci EL, Lipkin M, Newmark H, Holick MF, Garland FC: Vitamin D and prevention of breast cancer: pooled analysis. J Steroid Biochem Mol Biol 2007, 103:708-711.

4. Grant WB: Epidemiology of disease risks in relation to vitamin D insufficiency. Prog Biophys Mol Biol 2006, 92:65-79.

5. Grant WB: How strong is the evidence that solar ultraviolet $B$ and vitamin $D$ reduce the risk of cancer? An examination using Hill's criteria for causality. Dermato-Endocrinology 2009, 1:17-24.

6. Grant WB: A critical review of vitamin D and cancer: a report of the IARC working group on vitamin D. Dermato-Endocrinology 2009, 1:25-33.

7. Wang TJ, Pencina MJ, Booth SL, Jacques PF, Ingelsson E, Lanier K, Benjamin EJ, D'Agostino RB, Wolf M, Vasan RS: Vitamin D deficiency and risk of cardiovascular disease. Circulation 2008, 117:503-511.

8. Munger KL, Levin LI, Hollis BW, Howard NS, Ascherio A: Serum 25-hydroxyvitamin D levels and risk of multiple sclerosis. JAMA 2006, 296:2832-2838.

9. Lind L, Hanni A, Lithell H, Hvarfner A, Sorensen OH, Ljunghall S: Vitamin D is related to blood pressure and other cardiovascular risk factors in middle-aged men. Am J Hypertens 1995, 8:894-901.

10. Hypponen $E_{\text {, Laara }}$, Reunanen A, Jarvelin MR, Virtanen SM: Intake of vitamin D and risk of type 1 diabetes: a birth-cohort study. Lancet 2001, 358:1500-1503.
11. Chiu KC, Chu A, Go VL, Saad MF: Hypovitaminosis D is associated with insulin resistance and cell dysfunction. Am J Clin Nutr 2004, 79:820-825.

12. Sedrani SH: Low 25 -hydroxyvitamin $D$ and normal serum calcium concentrations in Saudi Arabia: Riyadh region. Ann Nutr Metab 1984, 28:181-185.

13. Marwaha RK, Tandon N, Reddy DR, Aggarwal R, Singh R, Sawhney RC, Saluja $B$, Ganie MA, Singh S: Vitamin D and bone mineral density status of healthy schoolchildren in northern India. Am J Clin Nutr 2005, 82:477-482.

14. El-Hajj Fuleihan G, Nabulsi M, Choucair M, Salamoun M, Hajj Shahine C, Kizirian A, Tannous R: Hypovitaminosis D in healthy schoolchildren. Pediatrics 2001, 107:E53.

15. McGrath JJ, Kimlin MG, Saha S, Eyles DW, Parisi AV: Vitamin D insufficiency in southeast Queensland. Med J Aust 2001, 174:150-151.

16. Sedrani SH, Elidrissy AW, Arabi KM: Sunlight and vitamin D status in normal Saudi subjects. Am J Clin Nutr 1983, 38:129-132.

17. Al-Turki H, Sadat-Ali M, Al-Elq A, Al-Mulhim F: 25-Hydroxyvitamin D levels among healthy Saudi Arabian women. Saudi Med J 2008, 29:1765-1768.

18. Sadat-Ali M, AlElq A, Al-Turki H, Al-Mulhim F, Al-Ali A: Vitamin D levels in healthy men in eastern Saudi Arabia. Ann Saudi Med 2009, 29:378-382.

19. Elsammak MY, Al-Wosaibi AA, Al-Howeish A, Alsaeed J: Vitamin d deficiency in Saudi Arabs. Horm Metab Res 2010, 42:364-368.

20. Ardawi M, Sibiany A, Bakhsh T, Qari M, Maimani A: High prevalence of vitamin D deficiency among healthy Saudi Arabian men: relationship to bone mineral density, parathyroid hormone, bone turnover markers, and lifestyle factors. Osteoporos Int 2012, 23:675-686.

21. Ardawi M, Qari M, Maimani A, Raddadi R: Vitamin D status in relation to obesity, bone mineral density, bone turnover markers and vitamin D receptor genotypes in healthy Saudi pre- and postmenopausal women. Osteoporos Int 2011, 22:463-475.

22. Al-Daghri NM, Al-Attas OS, Al-Okail MS, Alkharfy KM, Al-Yousef MA, Nadhrah HM, Sabico SB, Chrousos GP: Severe hypovitaminosis D is widespread and more common in non-diabetics than diabetics in Saudi adults. Saudi Med J 2010, 31:775-780.

23. Al-Elq A, Sadat-Ali M, Al-Turki H, Al-Mulhim F, Al-Ali A: Is there a relationship between body mass index and serum vitamin $D$ levels? Saudi Med J 2009, 301:542-546.

24. Arunabh S, Pollack S, Yeh J, Aloia JF: Body fat content and 25-hydroxyvitamin D levels in healthy women. $J$ Clin Endocrinol Metab 2003, 88:157-161.

25. Parikh SJ, Edelman M, Uwaifo Gl, Freedman RJ, Semega-Janneh M, Reynolds J, Yanovski JA: The relationship between obesity and serum 1, 25-dihydroxy vitamin D concentrations in healthy adults. $J$ Clin Endocrinol Metab 2004, 89:1196-1199.

26. McGill A, Stewart J, Lithander F, Strik S, Poppitt S: Relationships of low serum vitamin D3 with anthropometry and markers of the metabolic syndrome and diabetes in overweight and obesity. Nutr J 2008, 7:1-5.

27. Konradsen S, Jorde R, Ag H, Lindberg F, Hexeberg S: Serum 1,25-dihydroxy vitamin D is inversely associated with body mass index. Eur J Nutr 2008, 47:87-91.

28. Macdonald H, Mavroeidi A, Barr R, Black A, Fraser W, Reid D: Vitamin D status in postmenopausal women living at higher latitudes in the UK in relation to bone health, overweight, sunlight exposure and dietary vitamin D. Bone 2008, 42:996-1003.

29. Epstein S, Bell NH, Shary J, Shaw S, Greene A, Oexmann MJ: Evidence that obesity does not in-fluence the vitamin D-endocrine system in blacks. J Bone Miner Res 1986, 1:181-184.

30. Nesby-O'Dell S, Scanlon KS, Cogswell ME, Gillespie C, Hollis BW, Looker AC, Allen C, Doughertly C, Gunter EW, Bowman BA: Hypovitaminosis D prevalence and determinants among African American and white women of reproductive age: third National Health and Nutrition Examination Survey, 1988-1994. Am J Clin Nutr 2002, 76:187.

31. Shi H, Norman AW, Okamura WH, Anintida S, Zemel MB: 1a,25-dihydroxyvitamin D3 inhibits uncoupling protein 2 expression in human adipocytes. FASEB J 2002, 16:1808-1810.

32. Shi H, Norman W, Okamura WH, Sen A, Zemel MB: 1a,25-dihydroxyvitamin D3 modulates human adipocyte metabolism via nongenomic action. FASEB J 2001, 15:2751-2753.

33. Cumming RG, Cummings SR, Nevitt MC, Scott J, Ensrud KE, Vogt TM, Fox K Calcium intake and fracture risk: results from the study of osteoporotic fractures. Am J Epidemiol 1997, 145:926-934. 
34. Sowers MF, Wallace RB, Hollis BW, Lemke JH: Relationship between 1 , 25- dihydroxyvitamin D3 and blood pressure in a geographically defined population. Am J Clin Nutr 1988, 48:1053-1056.

35. Krause R, Buhring M, Hopfenmuller W, Holick MF, Sharma AM: Ultraviolet B and blood pressure. Lancet 1998, 352:709-710.

36. Pfeifer M, Begerow B, Minne HW, Nachtigall D, Hansen C: Effects of a short-term vitamin $D(3)$ and calcium supplementation on blood pressure and parathyroid hormone levels in elderly women. J Clin Endocrinol Metab 2001, 86:1633-1637.

37. Jorde $R$, Bonaa $K$ : Calcium from dairy products, vitamin $D$ intake, and blood pressure: the Tromso study. Am J Clin Nutr 2000, 71:1530-1535.

38. Forman JP, Bischoff-Ferrari HA, Willett WC, Stampfer MJ, Curhan GC: Vitamin $D$ intake and risk of incident hypertension results from three large prospective cohort studies. Hypertension 2005, 46:676-682

39. Scragg R, Sowers M, Bell C: Serum 25-hydroxyvitamin D, diabetes, and ethnicity in the Third National Health and Nutrition Examination Survey. Diabetes Care 2004, 27:2813-2818.

40. Ford ES, Ajani UA, McGuire LC, Liu S: Concentrations of serum vitamin D and the metabolic syndrome among U.S. adults. Diabetes Care 2005, 28:1228-1230.

41. Need AG, O'Loughlin PD, Horowitz M, Nordin BE: Relationship between fasting serum glucose, age, body mass index and serum 25 hydroxyvitamin D in postmenopausal women. Clin Endocrinol (Oxf) 2005 62:738-741.

42. Pittas G, Lau J, Hu F, Dawson-Hughes B: The role of vitamin D and calcium in type 2 diabetes. A systematic review and meta-analysis. J Clin Endocrinol Metab 2007, 92:2017-2029.

43. Hidayat $R$, Setiati $S$, Soewondo $P$ : The association between vitamin $D$ deficiency and type 2 diabetes mellitus in elderly patients. Acta Med Indones 2010, 42:123-129.

44. Gupta A, Brashear M, Johnson W: Prediabetes and prehypertension in healthy adults are associated with Low vitamin D levels. Diabetes Care 2011, 34:658-660.

45. Al-Daghri NM, Alkharfy KM, Al-Othman A, El-Kholie E, Moharram O, Alokail MS, Al-Saleh Y, Sabico S, Kumar S, Chrousos GP: Vitamin D supplementation as an adjuvant therapy for patients with T2DM: an 18-month prospective interventional study. Cardiovasc Diabetol 2012, 11:85.

46. Elzubier AG, AL-Shehry SZ: Too many vitamins for diabetics. World Health Forum 1997, 18:73-74.

47. Kienreich K, Tomaschitz A, Verheyen N, Pieber T, Gaksch M, Grubler MR, Pilz S: Vitamin D and Cardiovascular Disease. Nutrients 2013, 5:3005.

48. Abiaka C, Delghandi M, Kaur M, Al-Saleh M: Vitamin D status and anthropometric indices of an Omani study population. Sultan Qaboos Univ Med J 2013, 13:224-231.

49. Al-Daghri NM, Alkharfy KM, Al-Othman A, Yakout SM, Al-Saleh Y, Fouda M, Sabico S: Effect of non-pharmacologic vitamin D status correction on circulating bone markers in healthy overweight and obese Saudis. Molecules 2013, 18:10671-10680.

50. Dastani Z, Berger C, Langsetmo L, Fu L, Wong BY, Malik S, Goltzman D, Cole $D E$, Richards JB: In healthy adults, biological activity of vitamin $D$, as assessed by serum PTH, is largely independent of DBP concentrations. J Bone Miner Res 2013. [Epub ahead of print]

51. Bentli R, Taskapan H, Toktas H, Ulutas O, Ozkahrahman A, Comert M: Significant predictors of vitamin $D$ deficiency in inpatients and outpatients of a nephrology unit. Int J Endocrinol 2013, 2013:237869.

52. Al-Saleh Y, Al-Daghri NM, Alkharfy KM, Al-Attas OS, Alokail MS, Al-Othman A, Sabico S, Chrousos GP: Normal circulating PTH in Saudi healthy individuals with hypovitaminosis D. Horm Metab Res 2013, 45:43-46.

53. Al-Daghri NM, Al-Attas OS, Alokail MS, Alkharfy KM, El-Kholie E, Yousef M, Al-Othman A, Al-Saleh Y, Sabico S, Kumar S, Chrousos GP: Increased vitamin $D$ supplementation recommended during summer season in the gulf region: a counterintuitive seasonal effect in vitamin $D$ levels in adult, overweight and obese Middle Eastern residents. Clin Endocrinol (Oxf) 2012, 76:346-350

doi:10.1186/1471-2458-14-159

Cite this article as: Alfawaz et al:: Vitamin D status among patients visiting a tertiary care center in Riyadh, Saudi Arabia: a retrospective review of 3475 cases. BMC Public Health 2014 14:159.

\section{Submit your next manuscript to BioMed Central and take full advantage of:}

- Convenient online submission

- Thorough peer review

- No space constraints or color figure charges

- Immediate publication on acceptance

- Inclusion in PubMed, CAS, Scopus and Google Scholar

- Research which is freely available for redistribution 